\title{
THE CONSTRUCTION OF URBAN AND RURAL INTEGRATIVE CADASTRAL MANAGEMENT INFORMATION SYSTEM
}

\author{
XU De-jun ${ }^{\mathrm{a}, \mathrm{b}, \mathrm{c}}$, ZHONG Mei ${ }^{\mathrm{a}, \mathrm{b}}$, DU Qing-yun ${ }^{\mathrm{a}, \mathrm{b}}$

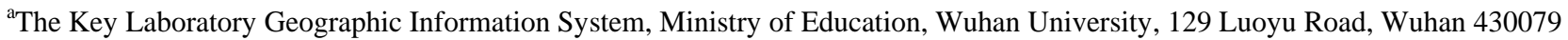 \\ ${ }^{\mathrm{b}}$ School of Resource and Environment Science, Wuhan University, 129 Luoyu Road, Wuhan 430079 \\ ${ }^{\mathrm{c}}$ The Bureau of Land Resource of Linhai,299 Renming Road, Zhejiang Linhai 317000
}

\section{Commission VI, WG VI/4}

KEY WORDS: Integration of Urban and Rural Area, Cadastral Management Information System, Digital Cadastral, Land Classification System

\begin{abstract}
:
Based on the present condition and developing trend of cadastral management of Linhai, The paper expatiates on the construction status of the Cadastral Management Information System on Integration of Urban and Rural area of Linhai, Zhe jiang. For a long time, urban and rural area are managed separately, and their database are established respectively, so it's very hard to update data synchronously. These problems can't be solved until cadastral management information system is established, which also makes cadastral product accord with new land classification system of urban and rural integration. Several issues are discussed: the objective, idea, principle of system design, the hardware and software environment, overall framework design, cadastral database structure design and function design, and so on.
\end{abstract}

\section{INTRODUCTION}

With Chinese city extending to country, the difference between city and country is decreasing. As a result, it is important for cadastral offices to pay more attention to urban and rural integrative cadastral management. According to actuality and trend of cadastral management, the author analyses the construction of modern urban and rural integrative cadastral management information system. For a long time, city and country are managed separately, and their database are established individually, so it's hard to update data synchronously. This problem can't be solved until urban and rural integrative modern cadastral management information system is established to accord with new land classification system both for city and country.

In this paper, taking the engineering construction of the Linhai Urban and Rural Integrative Modern Cadastral Management Information System as instance, the authors describe the design of software framework and function system of the Urban and Rural Integrative Modern Cadastral Management Information System, and carry on the detailed narration to the design of database.

\section{SYSTEM DESIGN OBJECTIVE}

The system design objective includes: (1)the need of cadastral information management; (2)enhance decision-making ability, quicken decision-making; (3) frequent and dynamic state monitor realization; (4)society applications.

\subsection{The Need of Cadastral Information Management}

The Cadastral Management Information System on Integration of Urban and Rural Area of Linhai started on 2005.6 by extensive investigation and sufficient gestation. The completion of the system construction will construct government affair management system, and accordingly regulate current organization functional division. So resource configuration will be much more optimized and the work efficiency and work quality will raise significantly.

\subsection{Enhance Decision-making Ability, Quicken Decision- making}

During economic construction and social development, the cadastres usually need relevant abundant information when analyzing macroscopically to make an administrative policy decision, and that the cadastre information is its basic data. The construction of cadastral management information system on integration of urban and rural area will establish data foundation on the depth development, extensive usage of land resource and offering information resource services towards the community.

\subsection{Frequent and Dynamic State Monitor Realization}

The land dynamic monitor is an important task of land management. There are a lot of troubles tot manage the alteration data by traditional techniques. After the construction of cadastral management information system on integration of urban and rural area is set up, the cadastre will become very convenient and everyday land dynamic land monitor can be implemented quickly and accurately. On the premise of collecting the relating information duly, the application system can quickly follow the progress condition of the land construction items, and check up the execution condition of the land leasing contract, punish illegal phenomena in time. Which is much significant for the criterion of land market and real estate, the maintenance of the serious land law and carry out land policy. 


\subsection{Society Applications}

After the construction of cadastral management information system on integration of urban and rural area is set up, the system will be open to the public and provide the real estate information for the public. With the extension of information collection and more and more extensive application, the system come into effect gradually to city management, social progress and economic development.

\section{THE IDEA, PRINCIPLE OF SYSTEM DESIGN}

In the course of system construction, several elements have be adequately considered: the advanced characteristics of hardware and software technique, the scientificity of model, the completeness of system, the flexibility of operation, the practicability of system, the openness and the extendibility.

\subsection{General Design Idea}

On the basis of the fact of cadastral information management, what are adequately considered includes the advanced characteristics of hardware and software technique, the scientificity of model, the information ,the rationality of structure, the completeness of system, the flexibility of operation, the practicability of system, the openness and the extendibility. The system construction lay scientific, real-time, practical as leading idea.

\subsection{Overall Design principle}

The construction of cadastral management information system on integration of urban and rural area of Linhai includes software development, database construction, network design and system maintenance and so on. It is a engineeringenormous and complicated information system project. All kinds of factors need be comprehensively considered, and need manage such problems as the relation of advancement and practicality, standardization and flexibility. The following principles have be followed when designed:

(1)Standardization: The system bases on the existing technique regulations of The Ministry of Land and Resources, and accords with criterion on working flow, accords with industry criterion on input and output, accords with industry criterion on software engineering and database construction.

(2)Practicability: The implementation of work without paper, accord with the working custom, operate simplicity, and offer complicated and strong operation function for the system vindicator.

(3)Advancement: the advancement of hardware equipments, software and technique means.

(4)Security: The system security is the important principle of system design. The system adopts authority management and network control, which assures that the whole software system is not illegally accessed and the subsystem is not illegally used.

(5)Dependability: includes the dependability of data and system run.

(6)Expansibility and Openness: The system has friendly interface, optimized system structure and flexible database system in order that all kinds of function modules can operate and run independently to the utmost, implements the maintenance and join of such database as topographic map, present land-use map , Cadastral map and so on. The system should have strong compatibility on output aspect, and can make conversions among different data formats.

\section{HARDWARE AND SOFTWARE ENVIRONMENT}

\subsection{Software Environment Analysis}

4.1.1 GIS Software: For the moment, the platform which cadastral information system depends on include the following several kinds: ARC/INFO, MAPINFO, GENAMAP, MAPGIS, and so on. MAPINFO is a desktop GIS, which is not good at support of huge data set, and its capability is also limited enough on spatial analysis. ARC/INFO is famous GIS product internationally, its capability of huge data set management and all kings of spatial analysis is strong, but high price and the request to English level and operation ability are the huge obstacle to use widely. MAPGIS, the home-grown excellent GIS software, get people more and more favour .

The construction of cadastral management information system on integration of urban and rural area should walk along the way of home-grown GIS, and take on a right GIS software as the platform. It is very significant to construct function-perfect multi-user network management information system. No matter what on economy, technology, and information security, we all must depend on ourselves GIS software. So it is the demand of constructing cadastral management information system to select MAPGIS as developing platform. MAPGIS is a GIS that the map and data is important comparably. It has strong map function and can satisfy all kinds of strict request of map edit and output, and its spatial analysis capability is also strong as ARC/INFO. Owing to MAPGIS is home-grown GIS software, its interface is Chinese, so operation is simple, moreover, it is expensive.

In view of the software technique advancement, system structure, the data management model, function, capability, supporting platform and the software corporation development and other factors, MAPGIS is chosen as software platform.

4.1.2 The storage structure of cadastral data based on relational database: The relational storage structure of cadastral data has the following advantages: (1) perfect data security, (2) easiness to transmit and share data; (3) the strong ability of record lock and security recovery etc. These advantages provide cadastral data an efficient management and overcome the demerits in developed cadastral management systems. To store cadastral data in relational database is actually feasible. Spatial ware and Oracle 9i are a data storage solution based on relational database, and have the ability to store cadastral data integrately. Of all the cadastral spatial data, the data about boundary nodes and property parcels is the most important, they should be stored in relational database. For the others', because they are less important and usually treated as backgrounds, they may be stored in GIS files. However, you can store them in relational database if necessary.

Oracle Enterprise Edition Release 9.0i is relational database management system which was developed by Oracle corporation. It has a history of nearly twenty years, and it is mainstream relational database management system. Oracle 
Enterprise Edition Release 9.0i offers efficient credible secure data management which is the same as all kinds of application, including the on-line transaction processing OLTP system of big charge and data-ware application system which takes query as primary function. At one time, based on object-relational design Oracle Enterprise Edition Release 9.0i makes managing complicated data (multimedia data, spatial data) possible. Oracle 9i provides system management tools, and can distribute data to all kinds of user availably and flexibly. Oracle 9i has needful refractivity of obtaining optimal capability from all practicable computer resources.

The access mode of database is multi-formal (e.g. ODBC,RDO and ADO etc.).Here the construction employs ODBC to connect database and MAPGIS OLE function to make a reality of map interaction. In fact, the above two key techniques involve a series of map object operations (e.g. inserting, deleting, updating, keeping map object and its spatial storage data synchronous etc.).

\subsection{Network Running Environment}

Based on the existing status of hardware and network, the system adopts the existing LAN among the bureau and other substations. The system network environment is shown as in Figure1, connecting the bureau and other substations by fiber, connecting the population consumer and the system by Internet in order to realize the resource sharing.

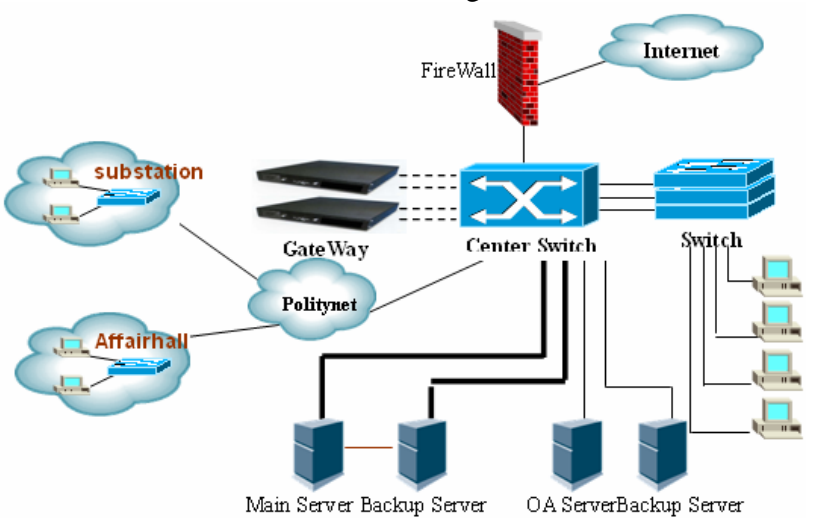

Figure 1. Network Running Environment topology

\section{HARDWARE AND SOFTWARE ENVIRONMENT}

\subsection{System Framework Design}

In view of the work characteristics of the bureau of land and resource of Linhai and the network connection request among the bureau, government and superior governing bureau, the system adopts the system framework of such network mode as principal B/S and adjective C/S (Figure 2).The interior function sections access information center by LAN and B/S mode, the information center manages data by $\mathrm{C} / \mathrm{S}$ mode. The bureau and exterior network are separated physically, and connected by Internet, and firewalls are set up, which all assures the security of system. The substations access the information center by B/S mode.

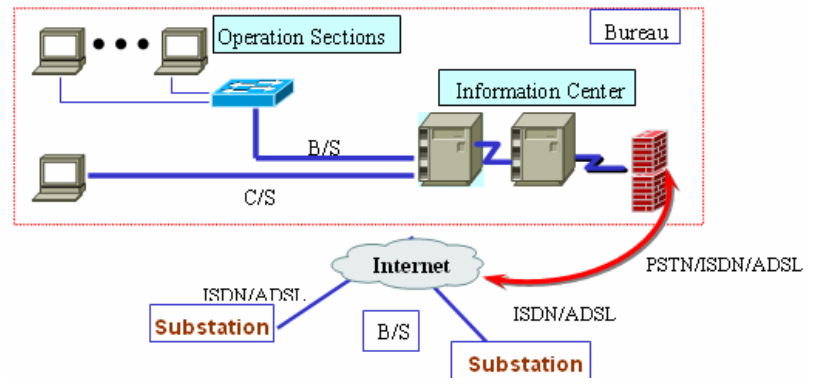

Figure 2. The system Framework

\subsection{Cadastral Database Design}

Based on the existing status of data scale, organization setting and function dividing, the project adopts the concentrative data management mode, the system database can realize the following request:

- The data uniform management;

- Import data form other source to the system expediently;

- Manage spatial and attribute data by object-relational database, insure the integration of spatial and non-spatial data, and realize the seamless organization of spatial data;

- Slove the generation, storage and management of historical data;

- Assure output of data resource safely and communion conditionally.

- Cadastral database includes base topographic database, cadastral map database, attribute database(Figure 3).

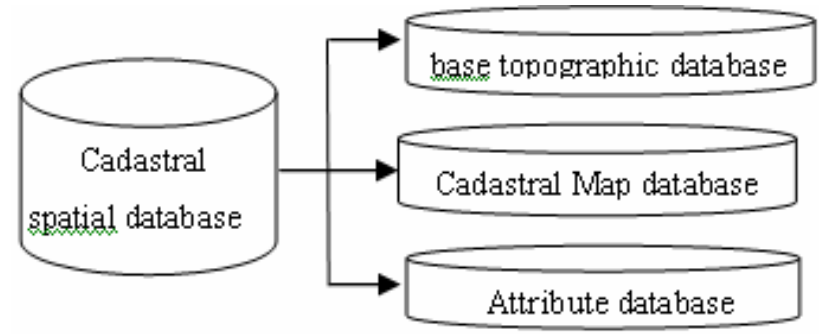

Figure 3. The Cadastral Database Structure

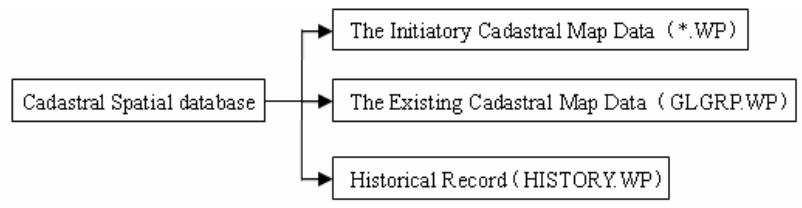

Figure 4. The Spatial Data Structure of Cadastral Database

\subsection{System Function Design}

The urban and rural integrative modern cadastral management information system of Linhai includes ten modules (Figure 5):

\section{CONCLUSION}

"Digital Land" is an important constitution of "Digital City", and "Digital Cadastral" is also the foundation of "Digital Land". The construction of urban and rural integrative modern 
cadastral management information system breaks the difference between city and country, advances the process of "Digital Cadastral" construction. Digital construction must consider the important development process of integration of urban and rural area. When "Digital Cadastral" is constructed, we must also consider constructing urban and rural integrative modern cadastral management information system. The construction product will offer abundant practice experience for the countrywide, also offer demonstrations for the spatial data application and services of land resource industries, even correlative industries.

\section{REFERENCES}

BAI Hui-ren, XU Xiao-peng, WANG Xie-yong. Research and development of the multipurpose model for the information system of cadastre. Journal of Dalian University.2005, 08,pp. $1-4$

Ma Gang, Ding Hua. Some Key Technology Study about Cadastre Information System Construction of Urban and Rural of Nanjing. Modern Surveying and Mapping. 2003,04:pp. $12-14$

YUAN Lin-wang, CHEN Ye, ZHOU Chun-lin. Heinrich Events Identified by Gamma Logging Curve During the Last Glacial
Period in Qaidam Basin. JOURNAL OF NANJING NORMAL UNIVERSITY (Natural Science). No 23(2),pp. 105-108

YANG Yong-chong, GUO Da-zhi. Spatio-temporal data model of urban and rural integrated cadastral information system. Jour. of Northwest Sci-Tech Univ. of Agri. and For. (Nat. Sci. Ed.), 2005,06, pp. 75-78

Burrough P A. Principles of Geographical Information Systems for Land Resources Assessment. Oxford University Press,1992,13-38

Han Wei-gang. Study on Establishing the Cadastral Database Based on Urban and Rural Cadastre United Management. Environmental \& Resources Sciences of Zhejiang University. 2004, 05

Jankowski, p., Integration geographical information systems and multiple criteria decision-making methods. Int. J. Geographical Information Systems, 1995

DIGITAL CADASTRAL MAPS IN LAND INFORMATION SYSTEMS Piotr Cichocinski, University of Mining and Metallurgy, Krakow, Poland,

http://www.kb.nl/infolev/liber/articles/cicho30-11.html

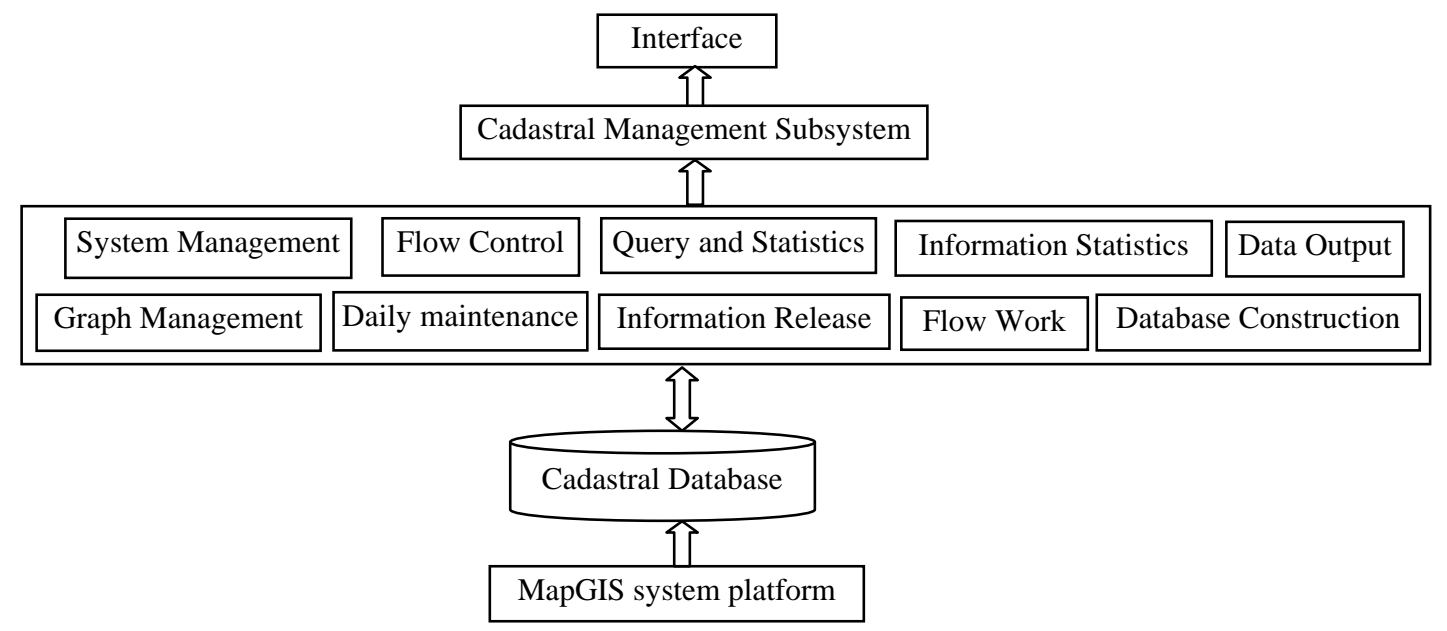

Figure 5. The System Overall Function Structure 